\title{
A identidade do agente comunitário de saúde: uma abordagem fenomenológica
}

\author{
The identity of the community healthcare agent: \\ a phenomenological approach
}

Rosane Guimarães Bachilli ${ }^{1}$

Ailton J osé Scavassa ${ }^{2}$

Wilza Carla Spiri ${ }^{3}$

1 Secretaria M unicipal de Saúde deCerquilho. Rua da Fazendinha 333, Centro. 18520-000 Cerquilho SP rosabachi@hotmail.com 2 Secretaria M unicipal de Saúdede M aringá 3Departamento de Enfermagem, Faculdade de M edicina deBotucatu UniversidadeEstadual Paulista de Botucatu.
Abstract The structure of Brazil's National $\mathrm{H}$ ealth System (SUS) is being firmed up through programs adding a new element to its multi-professional healthcare teams: Community $\mathrm{H}$ ealthcare Agents. This study examines psycho-social factors that are significant for the construction of this identity, from the standpoint of these Community $\mathrm{H}$ ealthcare Agents, using the hermeneutic phenomenology of Paul Ricoeur as its referencemethodology. Thesubjects of this survey were seven Community $\mathrm{H}$ ealthcare Agents who were asked during interviews (with informed consent and after approval by the Research Ethics Committee) to: 'Tell meabout your experience as Community Healthcare Agent'. The analysis of their replies indicated the following topics: previous experience; capacity-building for the job; bonding; building up expertise; gratifying experience; feelings of power(lessness); communications; daily work routines, personal growth; criticisms of the institution; user-agent experiences; and insertion into the social reality. The overall analysis disclosed the phenomenon through the convergence and divergence of the grouping of these topics, viewed from the standpoint of these Community Healthcare Agents and the psycho-social aspects constructing their identity.

Key words Identity, Community Healthcare Agent, Family $\mathrm{H}$ ealth Program, Phenomenology
Resumo A construção do Sistema Ú nico deSaúde ganhou sustentação com programas que engendraram a participação de um novo elemento na equipe multiprofissional, 0 agente comunitário de saúde. 0 objetivo deste estudo foi compreender os fatores psicossociais, segundo as perspectivas destes agentes, que são significativos na construção de sua identidade. 0 referencial metodológico adotado foi a fenomenologia hermenêutica de Paul Ricoeur. Os sujeitos da pesquisa foram seteagentes comunitários de saúdeque, apósaprovação do ComitêdeÉtica em Pesquisa econsentimento esclarecido, foram entrevistados com a questão norteadora: "Conte-me sua experiência como agente comunitário de saúde". A análise dos discursos resgatou os temas: "A experiência anterior", "A capacitação para o trabalho", "O estabelecimento de vínculo", "A conquista do conhecimento", "Experiência gratificante", "Sentimentos de (im) potência", "A comunicação", "O cotidiano do trabalho", "O crescimento pessoal", "A crítica da instituição", "A experiência do agente usuário", "A inserção na realidade social". A análise do geral desvelou o fenômeno a partir das convergências e divergências do agrupamento dos temas engendrando, na perspectiva do agente comunitário de saúde, os aspectos psicossociais que constroem a sua identidade.

Palavras-chave Identidade, Agente Comunitário de Saúde, Programa Saúde da Família, Fenomenologia 
Introdução

A construção do Sistema Único de Saúdeganhou sustentação a partir da implantação do Programa de Agentes Comunitários de Saúde (PACs), em 1991, e do Programa Saúde da Famíliaª , proposto em 1994. Tais estratégias estão alicerçadas sobre uma pedra angular - o Agente Comunitário de Saúde (ACS) - uma nova identidade social, ainda pouco estudada.

O ACS tornou-se categoria profissional em 10 de julho de 2002, após disputa de interesses sobre mercado de trabal ho e controle do exercício profissional, em quese debatiam mais do que os próprios ACS, outros atores políticos e sociais, numa discussão que se distanciou totalmente da questão essencial e existencial do agentecomunitário perantea sociedade e o serviço de saúde - a democratização do conhecimento.

O ACS é um cidadão que emerge das comunidades e se integra às equipes de saúde, sem trazer qual quer bagagem cultural ou técnica, específicas a essa área. Esse papel Ihe é conferido pela instituição executora das políticas públicas de saúde, dando-Ihe acesso a novas práticas, mediante incipientes dinâmicas de capacitação. Tal processo envolve uma parceria com outros espaços institucionais pertinentes ao contexto social onde esse agente atuará.

A parentemente, a própria instituição criou esse personagem com atribuições específicas elimitadas, como perfeita engrenagem, de encaixe ajustado a uma engenharia pré-estabelecida. Como se não coubesse ao homem a tarefa evolutiva e criativa, e aos grupos sociais a representação dasnecessidades sociais emergentes, 0 agente éfocado como produto/artefato institucional, da concep ção à gestão de suas atribuições e contribuições.

Cumpre então questionar: será 0 agente comunitário de saúde apenas um personagem instituído por uma estrutura social preexistente? $\mathrm{Ou}$, antes, vem ele a ser o canal de expressão de uma população quanto à necessidade imperiosa de exercer nova postura frente ao poder do conhecimento institucionalizado?

A indagação que deu origem a esse estudo começou em 1995, com o primeiro trabalho em PSF de um dos autores, que coordenava o treinamento introdutório de 64 agentes comunitários de saúde em uma cidade do interior de São Paulo. A multiplicidade de histórias de vida dos agentes se diluía na unidade de seu entusiasmo pelo que assumiam: o desafio do aprendizado, a perspectiva de ensinar seus semelhantes. Tais motivações, conhecidas dos autores pela análise das próprias trajetórias, refletiam-se nesses novos pares saídos das comunidades, sem jargões instrumentais que Ihes permitissem entender ou explicar a que vieram. Como perceber einteragir com o que verdadeiramente el es traziam ao novo contexto?

N ossa pesquisa confirmou a existência deuma nova atuação em saúde, deamplitudedesconhecida a muitos gestores e trabalhadores do Sistema Ú nico de Saúde. Porém, a inserção desses cidadãos não-detentores do saber acadêmico junto à equipe de saúde permeia todas as atividades de atenção primária. Silva et al. ${ }^{2}$ propõem que essa identidade seja construída menos pelas regras que pela relação entreprofissionais, indivíduos egrupos, na percepção do trabalho recíproco.

Os autores, médicos do PSF, fizeram este trabalho enquanto alunos do curso de Especialização em Saúdeda Família da Faculdade deM edicina da Universidade Estadual Paulista, de Botucatu, SP. A apropriação do saber conceitual levouos a se perceberem como parte viva e consciente do fenômeno das novas identidades, semelhante ao agente comunitário de saúde. M ais que considerações técnicas, filosóficas ou políticas, há nisso uma dimensão coletiva de ação-participação, no âmbito da consciência sanitária.

\section{A inqui etação e os objetivos do estudo}

Tendo como tema a identidade do agente comunitário desaúde, encontramos motivação no seguinte questionamento: Q uais fatores psicossociais são significativos, segundo a perspectiva dos agentes comunitários de saúde, para a construção de sua identidade?

Nosso objetivo no presente trabalho é compreender os fatores psicossociais, segundo as perspectivas dos agentes comunitários de saúde que são significativos na construção desua identidade.

Acreditamos poder contribuir com conhecimento específico edados significativos para a elaboração de metodologias que instrumentalizem os processos de seleção, capacitação e avaliação desses novos profissionais da saúde, e que contemplem as necessidades e expectativas inerentes a essa nova identidade social.

Nesse sentido, abrimo-nosà possibilidade de novas pesquisas, operacionais, dentro da perspectiva filosófica, que parte do olhar, da palavra e do sentir dos agentes comunitários de saúde, para a construção concreta de metodologias próprias ao seu desenvolvimento humano e profis- 
sional, a que os autores se propõem num próximo projeto.

\section{Trajetória metodológica}

A metodologia qualitativa foi escolhida para se pesquisar a partir do ponto de vista do sujeito, buscando atenuar a carência de material nessa perspectiva. A fenomenologia que "leva em conta o sentido histórico na sua pluralidade de significados" permitiu desvelar a essência das experiências dos sujeitos, impulsionados pela consciência e pelaintencionalidade.

A análise dos dados seguiu a hermenêutica de Paul Ricoeur, cumprindo-se as seguintes etapas: transcrição dos depoimentos; leituras das descrições em sua íntegra buscando um senso geral; apreensão das unidades de significado a partir da experiência do sujeito em seu mundo; expressão dos significados buscando convergências, divergências e idiossincrasias; síntese das unidades na estrutura do fenômeno, visando compreendê-lo. Em Ricoeur, aprendemos a buscar nos discursos as objetivações do mundo-vida dos sujeitos, que são os próprios agentes comunitários de saúde, cabendo aos autores decifrar o sentido oculto no sentido aparente, a partir da interpretação. A realidade existencial só aparece àqueles que se empenham como pessoa na trama histórica. A pesquisa desenvolveu-se em duas cidades do interior paulista: Cerquilho e Conchas. Com o aval do Comitê de Ética em Pesquisa da Faculdade de M edicina de Botucatu, fizeram-se sete entrevistas não-estruturadas, focalizadas, áudio gravadas, após consentimento livre e esclarecido e assegurados privacidade e anonimato aos ACS, seguindo-se a proposição: Conte-mea sua experiência como agente comunitário desaúde.

\section{Resultados}

A análise global dos depoimentos revelou significados em onze temas: experiência anterior; capacitação para o trabalho; a conquista do conhecimento; o cotidiano do trabalho; experiência gratificante; estabelecimento de vínculo; crescimento pessoal; a comunicação; sentimentos e (im) potência - a experiência do agente usuário; crítica à instituição; inserção na realidade social.

No tema experiência anterior, revelam-se os vestígios de antecedentes presentes nessa identidade em formação.
Parte dos entrevistados relata uma completa inexperiência de trabalho anterior, condizente com: idade, situação socioeconômica da família, prioridades da vida conjugal, da maternidade, das limitações próprias da história devida desses jovens:

“[...] eu nunca tinha trabalhado em ramo nenhum [...] nunca tinha [...] vivido num grupo de trabalho, nem sabia como era [...]." $(5,1)$

Muitos comentaram a busca intencional, de formação profissional, enquanto estudantes, fazendo frenteàs condições socioeconômicas limitantes do acesso ao ensino superior:

“[...] Não fiz faculdade [...] por falta de dinheiro [...] procurei fazer algo [...] que eu pudesse $[. .$.$] exercer." (2,1)$

Adequado, porém, nos parece não perder de vista o pano defundo: promovida por uma sociedade responsável pela continuidade do ensino aos adolescentes, inserida no plano de governo brasilei ro neoliberal dos últimos anos, a oportunização dada a essas jovens traz em si a disparidade para com as perspectivas reais de exercício profissional, gerando frustração ecrise de identidade profissional, precocemente:

"[...] entrei nesta área porque não tinha nada pra trabalhar [...] tava procurando emprego". $(3,1)$

A opção pelo trabalho de agente comunitário caracteriza-se, assim, não somente pela alternativa ao desemprego - um ato da vontade, mas principalmente pela atitude de presença na vida produtiva, que se lança em busca de uma nova valorização, uma nova categoria profissional.

Segundo Danese ${ }^{4}$, Ricoeur propõe uma transição filosófica do eu como vontade (ação ofensiva frente a um obstáculo), para o sujeito da interpretação criativa. I sso implica a problemática da centralidade da força ética da pessoa.

Com base nas entrevistas, verificamos que os agentes comunitários de saúde (ACS) desconheciam o ofício no qual ingressaram, em que pese 0 fato de residirem em cidades onde a implantação do Programa Saúde da Família ocorrera em cem por cento dos domicílios; a maioria não conhecia os agentes comunitários que atendiam à sua residência e mesmo suas especulações a este respeito não se confirmaram, conforme revelam as falas:

[...] tinha 0 agente comunitário [...] só que eu não tinha curiosidade de saber o que era o agente comunitário [...] ela chegava [...] eu não contava pra ela as coisas. $(4,1)$

Importante é lembrar que alguns dos entrevistados participaram do início da implantação do Programa Saúde da Família em suas respecti- 
vas cidades. Perceberam que era algo novo para eles, para os gestores e para os usuários, conforme expressaram:

"[...] quando eu entrei pra trabalhar, [...] era uma coisa que tava em experiência [...] nem eles sabiam o que era PSF [...] foi uma coisa nova". $(1,1)$

Somente durante a prática efetiva descobriram o que é ser agente comunitário de saúde, quando expressaram:

"[ ...] com o tempo vocêvai aprendendo". $(1,2)$

A percepção dos nossos entrevistados, ao tempo que eram população usuária, era fragmentada e distorcida com relação ao desempenho do agente comunitário: a maioria imaginava um trabalho burocrático ou protocolar, sem maior envolvimento com os assistidos ou com a equipe de saúde.

Ainda hoje, amplo contingente de trabal hadores da saúde, participantes do Sistema Ú nico de Saúde, porém não das equipes de Saúde da Família, desconhecem a amplitude e profundidade das ações empreendidas pelos ACS.

Pedrosa \& Teles 5 também apontaram: “[...] a resistência eas dificuldades iniciais foram substituídas pela participação nas atividades do programa $[\ldots] " .$.

A Secretaria de Políticas de Saúde observou: Por seus princípios, o Programa Saúde da Família é, nos últimos anos, a mais importante mudança estrutural já realizada na saúde pública no Brasil.

Um dos entrevistados relata sua experiência como usuário do PSF, tendo orientações de uma agente comunitária de saúde, referindo uma relação de identidade baseada no reconhecimento dos benefícios por ela prestados:

"[...] antes de eu me tornar uma agente comunitária [...] tivea experiência deser [...] "paciente" de uma agente comunitária [...]". (5,1)

A vivência da crise se faz presente no pano de fundo da história pessoal. A única agente que refereconscientemente a identificação com o papel deagente comunitária a partir deuma experiência de usuária é a mesma que se fez usuária no momento de crise identitária profunda, experimentando a vivência da atenção à saúde, sua e do outro dentro de um contexto totalmente estranho em sua hierarquia de valores.

A uma leitura mais acurada, parecem ainda significativas algumas considerações que revelam a expectativa de desenvolver ações em benefício de outras pessoas:

"[...] Achava que visitaria somente aquelas que necessitam [...]". $(2,1)$

Essa expectativa reforça a disposição de ser- vir o outro, conhecer e ajudar pessoas em suas necessidades, que implica para o sujeito na capacidade de sobreviver, sofrer, obter reconhecimento do que se fez precedente, permanecer criativamente fiel ao desenho da própria história de sua vida ${ }^{4}$.

Percebe-se assim que a escolha do papel de agente comunitário decorre antes das limitações e lacunas de escolhas anteriormente elaboradas (formação educacional, dedicação integral ao matrimônio e maternidade), do que da apropriação consciente de um espaço profissional, em resposta a experiências de crise identitária.

A seguir, analisaremos um significado fundamental para as agentes, bem como para fins depesquisa institucionalizada: a capacitação para o trabalho, ou seja, o acesso ao conhecimento queéofer ecido ao agente comunitário a partir de sua admissão ao serviço, questionando através de sua ótica a adequação desse processo à sua realidade individual e profissional.

Q uanto à capacitação para o trabalho, nossos agentes convergiram para apontar sua insuficiência:

"[...] um monte de informação, jogou tudo, né?" $(1,2)$

"[...] eu acho que para uma agente eu não tinha preparo". $(2,2)$

Contaram que os cursos falharam por não incluir dados da realidade local, por enfoque insuficiente na área dos relacionamentos e/ou psicológicos e por excesso de informações em tempo restrito. Singularmente, porém, sugeriram propostas de readequação destes cursos que poderiam ter periodicidade mensal, foco no relacional e descentralizados, que se podem ver nas falas dos ACS, a seguir:

[...] mais cursos nesta área, como se relacionar com as pessoas, como entender os problemas, mais cursos de capacitação mesmo. $(2,2)$

[...] se fosse al go mais descentralizado, tipo um curso para os agentes da vila tal, acho que teria mais efeito. $(2,2)$

Nesse contexto, temos uma defasagem entre o nível de aspiração do agente e a expectativa da instituição que o recebe, bem como a pequena disponibilidade institucional para 0 aprendizado do seu próprio papel.

Tomaz ${ }^{6}$ constata: 0 processo de qualificação do ACS ainda é desestruturado, fragmentado, e, na maioria das vezes, insuficiente para desenvolver as novas competências necessárias para 0 adequado desempenho de seu papel.

Pensamos que, por se tratar de uma forma de trabalho ao qual o domínio do saber técnico tem que estar emparelhado ao domínio do conheci- 
mento da área das ciências humanas, com menor possibilidade tecnológica, a capacitação para os ACS ainda émuito insuficiente. 0 próprio $M$ inistério da Saúde apregoa "a necessidade de educação continuada das equipes envolvidas na operacional ização da estratégia de Saúde da Família" .

N os espaços de educação continuada, encontram-se com freqüência os conteúdos tradicionais de conhecimento e prática na área da saúde, havendo dificuldade dese dar conta da totalidadedas finalidades colocadas para o PSF².

O M inistério da Saúde esclarece que "um dos principais objetivoségerar novas práticas de saúde, nas quais haja integração das ações clínicas e de saúde coletiva. Porém, não se pode conceber a organização de sistemas de saúde que conduzam à realização de novas práticas sem que, de forma concomitante, se invista em uma nova política de formação e num processo permanente de capacitação dos recursos humanos"1.

O significado resgatado no tema a conquista do conhecimento resulta da própria reinterpretação dos autores quanto ao significado capacitação.

"[...] eu gosto de saber mais, ler mais". (2,3);

"[...] me sinto bem dando a orientação pra pessoa, podendo saber mais coisas do que a pessoa $[\ldots]^{\prime \prime} .(4,3)$

A busca desatisfação dessa necessidade reflete-sena inserção profissional, guardando íntima relação com a escolha deste trabalho ou com a motivação pelo trabalho:

“[...] você pode saber o porquê que a pessoa [...] sofre de uma doença [...] como você pode ajudar". $(3,3)$

Este mesmo enfoque do caráter de reciprocidade da conquista do conhecimento entreo agente e a comunidade transparece na relação entre 0 agente e a equipe, caracterizando um aspecto de cumplicidade mencionado por $\mathrm{N}$ unes et al. ${ }^{7}: \mathrm{Ob}$ serva-se assim, uma maior cumplicidade entre os vários profissi onais que se sentem comprometidos com a resolução de problemas básicos de saúde e melhoria da condição de vida da população-alvo.

“[...] pergunto pra enfermeira ou pro médico e depois eu te dou resposta [...] eu sempre tenho uma resposta pra eles". $(4,3)$

Evidentemente também existem menções, por partedosACS, da ampliação do seu poder de resolutividade após serem incluídos no PSF. Alguns referem mesmo que o seu prestígio social aumentou?.

A necessidade da instituição apropriar-se do conhecimento trazido pelo agente comunitário oriundo da própria comunidade pode ser vista em alguns discursos dos agentes, mas não ga- rante a multiplicação desse conteúdo para dentro do ambiente institucional:

“[...] Pra saber o que é realmente ser agente comunitário de saúde procurei saber como tratar [...] as pessoas, conversar com elas". $(2,3)$

0 estudo de Nunes et al. ${ }^{7}$ faz a leitura dos sinais de superação dessa dificuldade, a partir da própria interação equipe-agente, traduzida em repercussões concretas de atitudes: Nota-se inclusive que, numa perspectiva ampliada, aquelas equipes de saúde da família que desenvolvem, pelo estreito contato com a realidade local, uma maior sensibilidade a diferenças sociais e culturais, le vando-as maisa sério, tendem a desenvolver dinâmicas extremamente favoráveis à miscigenação cultural.

Encontramos relevância em destacar o tema o cotidiano do trabal ho como significado uma vez que os ACS descrevem que, através da informação, da escuta, do conselho, da conversa, da conscientização para a prevenção, ao fazerem as visitas domiciliares, disponibiliza-se a abordagem dos problemas que se detectam, revelando que a conversa durante o trabalho implica uma postura de neutralidade no conflito doméstico, conforme revela na fala:

“[...] pragenteaconselhar uma pessoa, a gente não pode falar mal de nenhum dos lados". $(1,4)$

Outro ACS vê seu trabalho sujeito à limitação específica:

“[...] então acho que o agente de saúde éisto, a pessoa que tenta mudar maus hábitos das pessoas em relação à saúde que possam ser melhoradas". $(2,4)$

Até estratégias mais complexas são incorporadas ao que fazer no trabalho:

[...] o trabalho, na verdade, é de conscientização da população. Se vocêtiver consciência de prevenir, de ter uma qualidade de saúde bem melhor, que as pessoas possam procurar ter e possam vir a ter futuramente. $(3,4)$

“[...] a conversa é elemento imprescindível da atuação, ou seja, é uma conversa interessada, uma tecnologia não-material do trabalho"2.

Uma das impressões mais fortes e comuns a todos os relatos étraduzi da pelo significado desvelado no tema experiência gratificante, pois nesta perspectiva todos os agentes disseram desenvolver seu trabalho com prazer.

A gratificação ocorre porque permite conversar, orientar, conhecer pessoas, ajudá-las, as quais agradecem, reconhecendo a importância do ACS. Há o desejo de proporcionar à sua clientela mais saúde, do qual decorre um declarado sentimento de gratificação: 
$\mathrm{Na}$ visão de um dos agentes, é premissa para um trabalho efetivo o gostar do que se faz:

[...] Se você faz o que você gosta, você faz com amor. Se você faz uma coisa que você não gosta muito, vocênão desempenha bem o papel. $(1,5)$

Freire ${ }^{8}$ diz: "não posso desgostar do que faço sob pena de não fazê-lo bem".

Se uma parte significativa dos agentes considera o seu trabalho gratificante, quer pela possibilidade de ser útil, quer pelo apoio a uma população carente, sua atuação implica envolvimento pessoal e desgaste emocional ${ }^{2}$.

Podemos inferir que, à medida que fazem seu trabalho, os ACS passam a compreender mais e melhor as circunstâncias envolvidas na produção ou supressão da saúde para aquele contingente de pessoas às quais visitam. Diante disto, aprimoram seus recursos para contribuir, o que passa a ser gratificante porque produz resultados que culminam com a gratidão dos visitados. O conteúdo dos discursos de todas as entrevistadas é rico na referência à sensação de prazer e recompensa extraordinária (gratificação) conferida pelo ser-fazer do agente.

Valoriza-se o significado do prazer relacionado à atitude receptiva:

"[...] Cada vez que vocêescuta uma coisa que deixa você alegre no seu trabalho, faz você produzir cada vez mais". $(1,5)$

"[...] Como você quer que elas te ouçam, elas também querem que eu ouça elas". $(3,5)$

Um dos significados mais profundos da experiência e da identidade dos ACS revela-se no tema o estabelecimento de vínculo.

"[...] M as aquelas pessoas que se abrem mais pra você são pessoas que confiam em você, que te recebem, conversam de tudo". $(1,6)$

[...] o PSF propõe uma ampliação do lócus de interação em saúde, incorporando na sua prática 0 domićlio e espaços comunitários diversos. Tal característica vem contribuindo para o fortalecimento do vínculo entre profissionais das equipes e a comunidade [...] tais tarefas implicam no fortalecimento de vínculo com a família com uma dupla finalidade: levar o serviço de saúde mais próximo do contexto domiciliar e fortalecer a capacidade do enfrentamento dos problemas de saúde através da transmissão das informações e conhecimentos?

Essa confiança merece análise mais profunda, porque revela o caminho principal a ser percorrido pelo agente, no estabelecimento de relações interpessoais efetivas para realizar o seu trabalho, as quais constituem, não poucas vezes, 0 trabalho propriamente dito.

O pensamento de Ricoeur apud Danese ${ }^{4}$ nos leva a compreender o sujeito como si mesmo, voltado para o outro - destaca Ricoeur: 'o si é sempre complemento de qualquer outro [...]. A tribuo muita importância ao aspecto ético dessa dinâmica; existe sempre um outro em frente ao si, para o qual o si se empenha .

Tanto 0 agente quanto 0 usuário percorrem o caminho do vínculo que éa estima de si numa forma dialogal, quando o outro confirma para 0 si a própria estima. Esse processo fica bem descrito na afirmação: A estima desi [...] implica que cada um no mundo reconheça o eu digno de estima de si e que, na falta de uma comparação justa, 0 sujeito possa viver na recordação ou na espera ou na representação de cada um com quem tenha convivido ou Alguém de quem se tenha feito a experiência interior e lhe garanta essa estima9.

A narrativa das agentes transmite a percepção de que seu vínculo com o paciente preenche as necessidades afetivas do outro:

"[...] não têm na casa deles alguém que eles possam estar sentando e conversando como eles conversam com a gente". $(1,6)$

Somente assim se pode estabelecer uma verdadeira igualdade com respeito às diferenças e à fraqueza do outro: Sea desigualdade provém da debilidade do outro, do seu sofrimento é a compaixão que tende a restabelecer a reciprocidade, e mesmo ocorre que 'aquele que parece estar só a dar recebe mais quando dá, através da gratidão e do reconhecimento ${ }^{4}$.

Os ACS reconheceram que houve transformações pela conversa em ambos os pólos, deles mesmos e dos visitados.

"[...] a gente aprende a ter mais comunicação, aprende a escutar mais, porque elas querem te ouvir, mas elas também querem ser ouvidas". $(1,7)$

A reciprocidade do dar ereceber (solidariedade), estampada pelos agentes, constitui premissa básica do PSF podendo ser, sob nossa ótica, considerado seu aspecto filosófico. Não teria sentido uma atividade que visa a transformação do sujeito, imerso na família e na comunidade, sem que seus motores para tal (equipe do PSF) também sofressem alguma transformação. Através desta dialética delineiam-se patamares superados e a necessidade de ascensão a novos, para todos.

Para Ricoeur ${ }^{3}$, a questão da implicação dos reconhecimentos numa situação relacional assim se dá: "não se apreende jamais diretamente uma individualidade, mas somentesua diferença com relação a outra e a si mesma".

Nunes et al. ${ }^{7}$ contemplaram os fatos que agora verificamos, dizendo: A entrada no mundo fami- 
liar traz inevitavel mente consigo a intimidade das pessoas, o seu mundo privado, e, com ele, novas construções relacionais permeadas de significadose de sentimentos [...] as necessidades humanas e as de saúde, não se resumem às necessidades naturais (biológicas), estendendo-seàs existenciais (no sentido de necessidades de existência, de caráter social) e incluindo as humanas (amor, amizade, atividade moral).

Encontramos uma consigna que permeia todos os discursos e se reflete em outros significados, desvelado no tema o crescimento pessoal e profissional.

$M$ anifestam os ACS que o desempenho do trabal ho ao longo do tempo permitiu quese aprimorassem pela apreensão do trabalho em equipe e a possibilidade de serem criativos. Que, olhando criticamente para o início da atividade, detectaram que não entendiam a amplitude do seu papel, inclusive aspectos relativos à saúde:

[...] Porque quando a gente começou era difícil chegar, explicar; vocêter queexplicar algo quevocê não entendia plenamente, então foi um pouco difícil. H oje eu faço meu trabalho normalmente. $(1,8)$

A maioria refere como importantevalor agregado à capacidade de abordagem das pessoas, inclusive na esfera psicológica, ajudando-as em suas dificuldades.

“[...] Agora eu sou uma pessoa mais sociável [...] foi crescimento pessoal mesmo". $(1,8)$

A maioria dos ACS tem projetos de prosseguir estudos para aplicação na Equipe de Saúde da Família, desejando crescer dentro do PSF. Os obstáculos às suas pretensões são os recursos salariais considerados baixos e o pagamento de cursos superiores considerados altos:

[...] Procurar trabalhar na minha área eu ia gostar muito. No momento, não tenho condição financeira. M as eu gostaria. Eu gostaria de fazer faculdade de Nutrição [...]. $(1,8)$

[...] Estou pensando em fazer uma faculdade ano que vem. 0 salário, senão subir, aí não dá pra fazer a faculdade. Eu penso em crescer dentro do PSF mesmo. $(3,8)$

As pessoas entrevistadas revelam toda a modificação depostura e deprojetos devida a partir da apropriação do conhecimento formal, através da experiência do outro, do saber do outro, que integra o próprio dia-a-dia do agente. $A$ esse processo criativo refere-se: 0 problema da pessoa se explicita como problema da criatividade humana na capacidade infinita de repensar novas formas de mediação, seja como homem individual, seja como grupo 4 .

"[...] tive casos de pessoas que mudaram um pouquinho, e aquilo foi bom para elas". $(2,8)$

[...] se eu fosse só como moradora, então pra mim não tem problema [...] eu como agente penso: e aquelas pessoas ali? [...] eu comecei a ter uma visão mais ampla. $(3,8)$

A pós várias análises, resgatamos o significado de sentimentos e (im)potência - a experiência do agente-usuário, onde a onipotência e a frustração permeiam a subjetividade deum agente social, que mantém profunda relação de pertença com seu espaço: o espaço em queviveéo mesmo onde atua, as pessoas da sua realidade social são as mesmas para quem dirige as suas ações de cuidado. Essa concordância de universo físico, social e psicológico estimula o empenho de buscar, propor todo o bem viver desejado para o outro, como para si, numa ampliação profunda das aspirações à satisfação das necessidades, a nível relacional (presença do outro), biológico (espaço de sobrevivência tribal) e sociopolítico (o espaço para todos, em nível institucional).

"[...] trabalho e fala 'nossa, você não veio, que fal ta quefaz', então reconhecetambém”. $(3,9)$

A confiança no trabalho dos agentes traduzse ainda, segundo os mesmos, no atendimento às suasconvocações eno comparecimento quase maciço aos retornos agendados.

O papel tradicionalmente atribuído ao médico goza até hoje deimportância e diferenciação e, como os ACS recebem algum ensinamento daqueles, ascendem a um status diferenciado, conforme salientam: O bserva-se que a formação que recebem Ihes dá um sentimento orgulhoso de diferenciarem o seu conhecimento em relação ao conhecimento popular que dispunham previamente, o que lhes confere prestígio social, uma vez que o saber biomédico situa-se numa escala superior na hierarquia de saber da sociedade7.

Os agentes assim se expressam:

[...] Toda vida semprefalei: eu queria ser médica! Cuidar da saúdemental, da saúdefísica, da saúde emocional [...] acho muito importante porque o [...] paciente [...] confia muito no médico. $(4,9)$

A vocação biomédica é uma das mais carregadas de sentimentos onipotentes, uma vez que a ação dessas pessoas interfere na própria vida dos pacientes. No entanto, a apropriação subjetiva de capacidades onipotentes éum fenômeno que a cada dia se multiplica no mundo moderno, incentivada pelos órgãos de comunicação de massa.

Em contrapartida, incorpora uma postura mediadora de propostas entre o desejo da comunidade e as possibilidades institucionais:

"[...] deveria ter outro médico no posto pra 
tá atendendo esses eventuais [...]". $(7,9)$

Esse sentimento de pertença amplia as expectativas do próprio espaço, afirmando a posição especial do agente comunitário morador da sua área de atuação:

[...] Como eu já fui paciente, eu imagino assim [...] quando a gente mora na comunidade [...] a gente vê o que realmente tá precisando. E o PSF é isso. $(5,9)$

Segundo Silva $\&$ Dalmaso², a esse mesmo comprometimento onipotente corresponde freqüentemente a sensação dolorosa da impotência: No dia-a-dia, os agentes são colocados diante de contradições sociais, o que é 'muito pesado' e, por isso, eles fazem determinadas opções, segundo as exigências, as recompensas e suas referências.

É reconhecida também pelo ACS a limitação da sua práxis por não poder interferir diretamente em determinadas realidades sociais, vendo-se impotente:

"[...] Tem casos em que às vezes tem tanta pobreza, tanta mesmo, que a gente fica meio amarrado por não poder fazer nada". $(3,9)$

Esse sentimento de impotência é experimentado no confronto com as questões difíceis da realidade que, mesmo conhecidas, ganham nova dimensão quando se constituem num compromisso que transcende ao da vizinhança e da camaradagem, transformando-se num vínculo social:

"[...] foi difícil pra mim. Tinha vergonha de orientar [...] via coisa errada, mas eu não conseguia por serem meus vizinhos". $(1,9)$

Nunes et al. ${ }^{7}$ referem-se a um contexto muito peculiar nessa questão de identidade comunitária, detentora de espaço, saber e linguagem próprios, ao confrontar-se com as concepções e sentimentos do resto da equipe, instalando-se muitas vezes na sensação de desvalorização e incapacidade: U m segundo aspecto reportado, de forma direta ou velada, é o conflito de poder, que se instaura quando o ACS passa a dividir, e mesmo disputar, o seu lugar de prestígio na comunidade com os outros membros da equipe, principalmente com o médico.

[...] tem pessoas mais altas do que você [...] você depende dessas pessoas [...] enfermeira, o mé dico, até mesmo o chefe [...] mas o pouco de coisas que você consegue já é importante. $(4,9)$

Outro tema que se destaca, refere-se à inserção na realidade social, conforme revelam as falas a seguir:

[...] tem tanto [...] a classealta, a classemédia ea classebaixa. Então seaprende com astrêsclasses [...] a classe alta, por mais [...] resistência que ela tenha com você, pra não te receber, ela acaba te recebendo. É sua insistência, todo mês, você indo lá [...] ela acaba pegando em você uma confiança, que ela não tem em muitas pessoas. Com a própria família dela [...] A classemédia eu acho queéa classemais difícil de lidar [...]. Quem quer ser e não é, é difícil [...] aquele sem nada émuito fácil [...] você vê mesmo a diferença que tem, que émuita diferença! $(6,11)$

0 relato das agentes é rico na percepção das diferenças da realidade social, desdea discrepância de oportunidades e recursos entre as diferentes famílias, até mesmo a estratificação dessas diferenças conferida pelas classes sociais.

O utro tema resgatado na experiência vivida dos sujeitos do estudo refere-se à crítica à instituição que abrange desde a visada feita pelo ACS ao próprio PSF, tramitando no cenário institucional onde se observam várias relações interpessoais e gerais, bem como posturas críticas com relação ao cenário político, referente às políticas sociais.

Uma avaliação própria, respaldada no todo social, permitiu a nossos agentes ter uma visada diante da sua baixa remuneração profissional:

"[...] Isto que atrapalha muito, o pouco salário". $(1,10)$

Sobre o desvio de função, manifestaram:

"[...] a gente acaba fazendo mais do que 0 serviço do agente mesmo". $(1,10)$

Também questionaram os critérios administrativos do serviço com relação à demanda, ao respeito para com o papel e a figura do profissional, a falta de planejamento estratégico para responder às demandas sociais da comunidade:

“[...] o bairro é grande já! M il e trezentas famílias! Pra um médico? É bastante só pra um médico, mas épouco em relação a mil etrezentas famílias". $(7,10)$

Evidenciaram que o modelo dirigente, predominantementeautocrático, redunda em baixa produtividade do trabalho:

[...] Não adianta você chegar e impor nada, autoridade, não é assim. Se tiver alguma coisa errada a gente vai conversar, dar idéias, deixar a equipe tocar o trabalho, fazer crescer, dar incentivo. $(1,10)$

Analisaram que o programa necessita de me Ihorias:

"[...] E muita coisa tem que melhorar, não só os agentes, no geral, auxiliar, enfermeira, médico. A equipeinteira". $(2,1)$.

No entanto, na avaliação final concluíram que:

"[...] acho que este trabalho do PSF é uma coisa muito bem bolada para atender a população". $(1,10)$ 
Spiri ${ }^{10}$ acrescenta que, do ponto de vista do sistema capitalista: [...] os profi ssionais que agregam ao trabalho com o paciente, além do corpo, outras dimensões simbólicas cujos valores não são dimensionáveis como: amor, compaixão, sensibilidade, compromisso, cumplicidade humana, embora inegavelmente necessários, não têm preço e portanto não se pagam.

\section{Considerações finais}

Os resultados revelam a identidade do agente comunitário de saúde construída num processo de transformação de si mesmo através da alteridade, ilustrada subjetivamente pelo relato da agente:

"[...] "éum pouco de [...] a gentesesentir um pouco deles [...] a genteéum pouquinho decada um deles, a gente faz parte deles, sabe?" (4)

Essa dialética ocorre entre pares e dentro da instituição.

Toda hermenêutica vem assim a ser, explicitamente ou implicitamente, compreensão de si mesmo pela via mediada pela compreensão do outro ${ }^{3}$. A riqueza desse significado transcende à experiência do agente, atingindo os autores nessa transformação do ser. Tal reação ér reflexo de uma filosofia que deve passar da interpretação do mundo para a transformação, o sujeito que interpreta eao mesmo tempo é interpretado na transformação do mundo porque está [...] empenhado à atividade recriadora de um mundo novo9.

Este arranjo identitário está alicerçado nestes agentes ao persistirem no trabalho, não obstante reveses e lutas diárias, com baixa remuneração, dando consistência ao modo de se fazer que os caracteriza como trabalhadores da saúde eque a par disto construíram um saber operante que é conformado no exercício do seu trabalho.

Em termos sociais, a identidade solidária se apresenta alterando a dinâmica local visando produzir efeitos positivos na consecução de re sultados favoráveis aos anseios que são proclamados na comunidade por meio das famílias. Para a conformação da identidade pessoal, o agente exercita um infindável processo deidentificações com o meio no qual transita. No desenvolvimento de suas atividades percebem-setransformados, tanto em sua identidade privada quanto social, ao se verem como representantes do sistema de saúde, construindo uma identidade profissional, nova também para o Brasil.

Compreendemos que a identidade do agente comunitário de saúde é uma construção que se aventura em novos caminhos, se apropria de um saber anteriormente excluído do seu fazer e do seu grupo interacional, vive encontros e desencontros com os parceiros de trabalho nos momentos em que a reciprocidade se alterna entre os iguais, os desi guais e os "insubstituíveis" epropõe novos limites que favorecem o caminho de outros, promovendo o desassombro necessário para o desenvolvimento eo crescimento interior.

Vislumbramos assim o caminho para elaboração de metodologiasúteisaos processos deeducação continuada deagentes comunitários de saúde e de suas equipes. Ainda que se disponha de pouca tradição em associar conteúdos filosóficos às atividades de capacitação em saúde, há que se buscar a apropriação possível dessa ferramenta humana natural: a consciência plenificada através da alteridade. Há que se empenhar nesse empoderamento, o do conhecimento, de forma democrática, como nos solicita a sociedade brasileira no papel personificado pelos agentes comunitários de saúde. Com eles, nos propomos a um próximo projeto depesquisa, operacional, deplanejamento pedagógico e elaboração de material didático experimental, a ser utilizado em processos de capacitação de ACS, a fim de comprovar a essência dessa experiência eagregar aos processos educacionais um diferencial: a realidade existencial daquele a quem se destina a educação e que participa da construção do conhecimento. 


\section{Colaboradores}

RG Bachilli, AJ Scavassa eWC Spiri participaram igualmente de todas as etapas da elaboração do artigo.

\section{Referências}

1. Brasil. Ministério da Saúde. O Programa Saúde da Família. [acessado 2002 Out 10]. Disponível em: http://www.portalsaude.gov.br

2. Silva JA, Dalmaso ASW. Agente Comunitário de Saúde: 0 ser, o saber, o fazer. Rio de Janeiro: Fiocruz; 2002.

3. Ricoeur P. Interpretação e ideologias. Rio de Janeiro: Editora Francisco Alves; 1990.

4. Danese A. II Contributo de Ricoeur al personalismo. Reflexão 1997; 69:35-72.

5. Pedrosa JIF, Teles JBM. Consenso e diferenças em equipes do Programa Saúde da Família. Revista de Saúde Pública 2001; 35(3): 303-11.

6. Tomaz JBS. O agente comunitário de saúde não deve ser um "super-herói". Interface - Comunic, Saúde, Educ 2002; 6(10):84-90.

7. Nunes MO, Trad LB, Almeida BA, Homem CR, Melo MCIC.O agente comunitário de saúde: construção da identidade desse personagem híbrido e polifônico. Cad Saúde Pública 2002; 18(6):1639-46.

8. Freire P. Pedagogia da autonomia: saberes necessários à prática educativa. São Paulo: Editora Paz e Terra; 2002.

9. Di Nicola GP. A proposito del concetto di reciprocitá in Paul Ricoeur. Utopia e analogia. Reflexão 1997; 69:73-99.

10. Spiri WC. Trabalho em equipe: 0 vivencial da equipe de reabilitação na fissura lábio-palatal [tese de doutorado]. São Paulo (SP): Escola de Enfermagem, Universidade de São Paulo; 2001.

Artigo apresentado em 15/02/2006

Aprovado em 12/05/2006

Versão final apresentada em 20/07/2006 